\title{
Reinforcer Pathology and Response to Contingency Management for Smoking Cessation
}

AQ: au AQ: 1

\author{
Alba González-Roz, Ángel García-Pérez, Sara Weidberg, Gema Aonso-Diego, and Roberto Secades-Villa \\ University of Oviedo
}

\begin{abstract}
Background: The recognition of the interplay between cigarette demand and impulsivity as a proxy of reinforcer pathology (RP) has prompted studies that assess these 2 constructs. Scarce research has examined their interrelation within clinical contexts. This secondary analysis sought to identify different types of treatment-seeking smokers based on cigarette demand and delay discounting and examine their differential response to contingency management (CM). Method: The dataset included 305 participants (68\% female) receiving either a cognitive-behavioral treatment (CBT) or CBT + CM. A cluster analysis based on the bifactorial structure of a cigarette purchase task (i.e., psychological inertia and persistence) and delay discounting (base-10 logarithmic transformation of the area under the curve) was conducted. Clusters were compared in abstinence rates at posttreatment and 6-month follow-up. Results: Two RP subgroups emerged, Cluster $1(n=128)$ and Cluster $2(n=177)$, which were interpreted as "individuals with excessive tobacco valuation" and "steep discounters," respectively. At 8 weeks, the percentage of abstinent individuals was higher in those in Cluster 2 compared to those in Cluster 1 ( $76.3 \%$ vs. $\left.61 \% ; \chi^{2}=8.291, p=.004, \phi=.16\right)$. The nonsignificant effect of treatment condition on cessation outcomes indicated that both clusters equally benefited from CBT or CBT + CM. Conclusions: Support was reached for the generalizability of CBT and CM irrespective of patients' RP subtype. The fact that CM did not enhance abstinence outcomes beyond those obtained with CBT alone, underscores the need to evaluate the effect of innovative treatment procedures tailored to these RP phenotypes.
\end{abstract}

Keywords: contingency management, reinforcer pathology, smoking, delay discounting, cigarette demand

Research on the etiology and treatment of nicotine dependence has recently drawn from the reinforcer pathology (RP) framework (Bickel, Jarmolowicz, Mueller, \& Gatchalian, 2011; Murphy et al., 2017). RP conceptualizes nicotine dependence as an altered reward process that renders individuals to overvalue nicotine use (i.e., drug demand) and/or prefer small immediate rewards (i.e., impulsive choice; Bickel, Johnson, Koffarnus, MacKillop, \& Murphy,

Editor's Note. Catherine Stanger served as the action editor for this article.-TC

(D) Alba González-Roz, Ángel García-Pérez, Sara Weidberg, Gema Aonso-Diego, and Roberto Secades-Villa, Department of Psychology, University of Oviedo.

This research was supported by the National Agency of Research of the Spanish Ministry of Science, Innovation, and Universities and the Euro-

AQ: 7 pean Regional Development Fund MINECO/FEDER (Grants PSI201122804, PSI2015-64371-P, BES-2016-076663, FPU17-00659, FPU15-

AQ: 8 04327). The authors report no conflict of interest. Some of the data and contents included in the manuscript have been presented at the 2019 CPDD Annual Scientific Meeting (San Antonio, TX) and at the 2019 NIDA International Forum (San Antonio, TX) in a poster format.

Correspondence concerning this article should be addressed to Alba González-Roz, Department of Psychology, University of Oviedo, Plaza Feijóo s/n 33003, Oviedo, Spain. E-mail: albagroz@cop.es
2014). Stemming from the field of behavioral economics, these two behaviors have been traditionally assessed through drug demand and delay discounting (DD) procedures (Koffarnus \& Kaplan, 2018).

Contingency management $(\mathrm{CM})$ is a behavioral intervention based on operant conditioning that uses tangible incentives (i.e., vouchers) to reinforce specific behaviors, such as submission of drug-negative biological specimen samples (Cahill, Hartmann-Boyce, \& Perera, 2015; McPherson et al., 2018). CM's efficacy for smoking cessation is well established and has been proven to promote high cessation rates at both short- (Petry, Alessi, Olmstead, Rash, \& Zajac, 2017) and long-term follow-up (Sayegh, Huey, Zara, \& Jhaveri, 2017; SecadesVilla, López-Núñez, Weidberg, González-Roz, \& Alonso-Pérez, 2019). Nevertheless, questions remain about the subgroups for which this intervention may be most effective and best targeted (Forster, Dephilippis, \& Forman, 2019). Previous studies, several of them by Dr. Petry and colleagues, have demonstrated that CM is effective regardless of income level (López-Núñez, Secades-Villa, PeñaSuárez, Fernández-Artamendi, \& Weidberg, 2017; Rash, Petry, \& Alessi, 2018), severe mental health conditions (Japuntich et al., 2019; Petry, Alessi, \& Rash, 2013; Tidey, Rohsenow, Kaplan, Swift, \& Reid, 2011), and concomitant drug use (Alessi \& Petry, 2014; Cooney et al., 2017; Rohsenow, Martin, Tidey, Colby, \& Monti, 2017).

Incipient research has stressed that steeper DD and high cigarette demand lead to poor short-term cessation rates, which fall below 53\% (Barlow, McKee, Reeves, Galea, \& Stuckler, 2017; 
Harvanko, Strickland, Slone, Shelton, \& Reynolds, 2019; Krishnan-Sarin et al., 2007; Secades-Villa, Pericot-Valverde, \& Weidberg, 2016). Against this background, there is some preliminary evidence suggesting that high-magnitude reward CM treatments are promising for reducing cigarette use in highly impulsive individuals (Renaud \& Halpern, 2010; Tomko, Bountress, \& Gray, 2016). However, despite the recognition of the synergistic effects of impulsivity and cigarette demand in accounting for RP (Amlung \& MacKillop, 2014), we know of no studies to date investigating how these two key interrelated behavioral repertories affect CM response.

More broadly, research on tobacco demand and DD has acknowledged several methodological problems that arise when it comes to assessing their relationship. Such problems pertain to multicollinearity and Type I error (Mackillop et al., 2016). The use of either specific cigarette purchase task (CPT) indices (e.g., $\mathrm{O}_{\max }$, intensity) or the area under the tobacco demand curve are two contemporary approaches that mitigate the abovementioned problems (Amlung, Yurasek, McCarty, MacKillop, \& Murphy, 2015; Nighbor et al., 2019; Weidberg, SecadesVilla, García-Pérez, González-Roz, \& Fernández-Hermida, 2019). However, these approaches deprioritize one index in favor of another, imply a loss of information and substantially deviate from the multidimensional nature of the relative reinforcing efficacy construct (Bickel, Marsch, \& Carroll, 2000). Using the principal components of CPT is a good compromise between the two latter approaches. This approach consists of reducing the five indices (i.e., breakpoint, $\mathrm{O}_{\max }, \mathrm{P}_{\max }$, elastic-

AQ: 2 ity, and elasticity) to fewer demand indicators. Although indices' loadings and nomenclatures seem to differ depending on sample characteristics, research consistently evinces a bifactorial structure of CPT (Bidwell, MacKillop, Murphy, Tidey, \& Colby, 2012; O'Connor et al., 2016), which reflects volumetric (i.e., maximum response rate of tobacco use) and persistence (i.e., resistance to cease the behavior) factors in consumption dimensions. In a previous study (see González-Roz, SecadesVilla, Weidberg, García-Pérez, \& Reed, 2018), support for a specific CPT structure among depressed smokers emerged: psychological inertia (conceptualized as resistance to cease using tobacco even when effective treatments are delivered) and persistence (reflecting both individuals' maximum response rate and insensitivity to increases in costs). Importantly, these components performed better over individual demand indices in terms of accurately characterizing the reinforcing efficacy of nicotine. Due to the scarcity of research conducted on the latent structure of CPT and its value for predicting cessation outcomes, its use within clinical research represents a timely and pressing need.

Inspired by Petry's work in the field of behavioral economics, this study sought to extend evidence on CM by examining for the first time (a) whether different typologies of smokers exist based on DD and cigarette demand latent factors and (b) whether the identified subgroups of smokers respond equally to a cognitive-

AQ: 3 behavioral treatment (CBT) and CBT + CM for smoking abstinence. As identifying subgroups of patients with different RP levels offers the opportunity to precisely tailor tobacco cessation interventions to patients' characteristics, it is expected that this study will provide insight into effective procedures for enhancing abstinence rates.

\section{Method}

\section{Participants and Procedure}

This secondary analysis comprised 305 treatment-seeking smokers recruited from two smoking cessation trials that examined the effect of 6- and 8-week CBT and CBT + CM programs for reinforcing abstinence (González-Roz et al., 2018; Secades-Villa, García-Rodríguez, López-Núñez, Alonso-Pérez, \& FernándezHermida, 2014). CM conditions incorporated an escalating magnitude of reinforcement and participants could potentially earn US\$307 or US\$342 depending on the study assignment. No significant differences emerged in smoking status based on $\mathrm{CM}$ intensity at either short- $(p=.25)$ or long-term follow-up ( $p=$ .63 ). To be eligible, participants in the two trials were required to meet the same inclusion criteria: (a) to be aged 18 or over, (b) to self-report smoking at least 10 cigarettes per day at the time of the intake assessment, and (c) to meet a diagnosis of nicotine dependence as per the Diagnostic and Statistical Manual of Mental Disorders (4th ed., text rev.) criteria (American Psychiatric Association, 2000). Individuals reporting mental health disorders and/or abuse of a substance other than nicotine were excluded from the studies and referred to other community cessation support resources. Study protocols were approved by the ethics review board of the community (Number 124/15). Table 1 displays the sociode- T1 mographic, psychological, and smoking-related characteristics of the study sample.

\section{Assessment}

During a single 60-min assessment session, which occurred 1 week before treatment onset, participants filled out a battery of questions to gather data on both demographics (e.g., sex, age, monthly income, employment status) and smoking behavior (e.g., cigarettes smoked per day and years of regular smoking). The Fagerström test for Nicotine Dependence (Heatherton, Kozlowski, Frecker, \& Fagerström, 1991) was used as a measure of nicotine dependence severity.

A DD task and a 19 item CPT adapted from MacKillop et al. (2008) were used as measures of RP. The 19-item CPT contains 19 prices from US $\$ 0$ (i.e., free) to US $\$ 1,136$ (i.e., €1,000) and asks participants to inform on the number of cigarettes they would smoke per day at each of the given prices. Raw data from this task yields four observed cigarette demand indicators (breakpoint, $\mathrm{O}_{\max }, \mathrm{P}_{\max }$, and intensity), and one which needs to be derived (i.e., elasticity). $\mathrm{O}_{\max }, \mathrm{P}_{\max }$ and breakpoint essentially capture the economic aspects of demand, which pertain to maximum consumption, its associated price and the exact price that causes individuals to cease the behavior. Intensity represents the overall consumption level when no cost (i.e., neither financial nor personal effort) exists, and elasticity informs on participants' demand sensitivity to increases in costs.

DD was assessed using a laptop and was presented as a choice of money that ranged between US $\$ 11.47$ and US $\$ 1,136$ (i.e., between $€ 10$ and $€ 1,000)$ after a fixed delay, versus various amounts of money available immediately at six delays: 1 day, 1 week, 1 month, 6 months, 5 years, and 25 years. A titration procedure which has previously been used in the DD literature was adopted (Holt, Green, \& Myerson, 2012). This method takes the 
Table 1

Participants' Baseline Characteristics $(N=305)$

\begin{tabular}{|c|c|c|c|}
\hline Characteristic & $M(S D)$ & $M d n$ (interquartile range) & $\%$ \\
\hline Sex (\% female) & & & 68 \\
\hline Age, years & $48.69(11.81)$ & & \\
\hline Employment status (\% employed) & & & 61 \\
\hline \multicolumn{4}{|l|}{ Monthly income } \\
\hline$\leq \$ 692$ & & & 27.5 \\
\hline$\$ 693-\$ 1,383$ & & & 29.5 \\
\hline$\$ 1,384-\$ 2,305$ & & & 34.6 \\
\hline$\geq \$ 2,306$ & & & 8.5 \\
\hline Cigarettes per day & $21.40(8.43)$ & & \\
\hline Years of regular smoking & $29.36(11.70)$ & & \\
\hline Previous 24-hr quit attempts & $2.17(2.75)$ & & \\
\hline FTND & $6.00(1.85)$ & & \\
\hline $\mathrm{CO}(\mathrm{ppm})$ & $20.76(13.34)$ & & \\
\hline Cotinine (ng/mL) & $2,294(1,962)$ & & \\
\hline BDI-II & $20.33(12.85)$ & & \\
\hline AUClogd & $.38(.27)$ & & \\
\hline Psychological inertia & & $-.06(1.19)$ & \\
\hline Persistence & & $.02(1.14)$ & \\
\hline
\end{tabular}

Note. $\quad$ FTND $=$ Fagerström Test for Nicotine Dependence $\mathrm{CO}(\mathrm{ppm})=$ carbon monoxide in parts per million; BDI-II = second version of the Beck Depression Inventory; AUClogd $=$ base-10 logarithmic transformation of the area under the curve.

lower and upper limit of possible values and divides this total range by 2,3 , or 4 to obtain an interval value. The value of the immediate option was one interval value above or below the upper and lower limits.

\section{Treatment Response Outcomes}

Treatment response was defined as being abstinent at both posttreatment and 6-month follow-up visits. Two measures of abstinence are provided: 7-day point-prevalence (i.e., being abstinent for at least 7 days prior to the assessment) and continuous abstinence (i.e., the mean number of days of complete abstinence since the quit day). Readings of carbon monoxide $(\mathrm{CO}) \leq 4 \mathrm{ppm}$ and cotinine samples $\leq 80 \mathrm{ng} / \mathrm{mL}$ confirmed self-reported smoking abstinence.

\section{Statistical Analysis}

Descriptive statistical analyses were conducted to analyze participants' baseline characteristics. A thorough preliminary analysis was conducted at first to identify the presence of nonsystematic CPT (see Stein, Koffarnus, Snider, Quisenberry, \& Bickel, 2015) and DD data (see Johnson \& Bickel, 2008). As a result, none of the participants were excluded due to nonsystematic CPT data but nine were due to nonsystematic discounting $\left(N_{\text {nonmonotonicity }}=3\right.$; $N_{\text {nondiscounting }}=6$ ), thus leaving 305 for inclusion in the purported analyses. Five CPT demand indices (i.e., breakpoint, $\mathrm{O}_{\max }, \mathrm{P}_{\max }$, intensity, and elasticity) were computed. All were observed except elasticity, which was derived using the Koffarnus, Franck, Stein, and Bickel (2015) demand equation using a constant $k$ value equal to 3.82 that resulted from subtracting mean consumption at the lowest price ( $\log _{10}$ transformed) from mean consumption at the highest price ( $\log _{10}$ transformed): $Q=Q_{0} \times 10^{k\left(e^{-a Q_{0} C}-1\right)}$. Both raw CPT data and individual demand indices (i.e., breakpoint, $\mathrm{O}_{\max }$, $\mathrm{P}_{\text {max }}$, elasticity, and intensity) were examined for the presence of outliers. Fourteen outliers $(4.59 \% ; 14 / 305)$ were identified and thus replaced by their highest nonoutlier value plus 1 unit. Afterward, CPT variables were log-transformed so as to improve the marked skewness and kurtosis (after logtransformation, skewness ranged between -0.568 and 0.778 ; kurtosis ranged between -0.341 and 1.451 ).

Given preliminary evidence supporting a bifactorial latent structure of CPT (i.e., persistence and amplitude) in cigarette smokers (Bidwell et al., 2012; O'Connor et al., 2016), a principal component analysis (PCA) with oblique rotation (oblimin) was performed to examine whether or not these latent components of CPT held for the study sample. CPT variables (breakpoint, $\mathrm{O}_{\max }, \mathrm{P}_{\max }$, elasticity, and intensity) were standardized and entered into the PCA. Barlett's sphericity and Kaiser-Meyer-Olkin indices were used as proxies of data adequacy for PCA. Indices' loadings across CPT factors were set at a cut-off of $\geq .32$ (see Tabachnick \& Fidell, 2000). The regression method was implemented in the PCA to calculate factor scores $(M=1 ; S D=2)$.

The DD rates were measured by the base-10 logarithmic transformation of the area under the curve (AUClogd). This index is a newly proposed indicator of discounting that overcomes the unbalanced contribution of each point of indifference in the Myerson, Green, and Warusawitharana (2001) procedure (see Borges, Kuang, Milhorn, \& Yi, 2016). It was calculated by dividing each logged delay by the longest delay (25 years). Values range between 0 and 1, with lower values indicating greater discounting.

The HPCLUS procedure in SAS software for k-means clustering and least squares estimation to compute the cluster centroids was used to identify clusters of smokers on the basis of the following variables: psychological inertia, persistence, and the AUClogd index. This method identifies clusters of individuals based on distances that are computed from quantitative variables (SAS Institute Inc., 2016). One of the advantages of using the HPCLUS procedure is that it performs well with relatively small 
sample sizes and provides a single indicator for estimating the adequate number of clusters: the aligned box criterion.

Clusters were externally validated through comparisons of sociodemographic factors (i.e., sex, age, employment status and monthly income), smoking-related features (i.e., cigarettes per day, nicotine dependence, years of regular smoking, number of prior 24-hr quit attempts, CO, and cotinine), and depressive symptoms, using a set of chi-square and $t$ tests analyses. Differences across groups in the percentage of abstinent patients and days of continuous abstinence were also assessed at both posttreatment and 6-month follow-up. Cohen's $D$, Cramer's $V$, and phi values were used as measures of effect size for $t$ tests and chi-square analyses, as appropriate.

Lastly, separate binary regression analyses were performed for assessing the clusters' treatment response (i.e., abstinent vs. smoker) at the posttreatment and 6-month follow-up by treatment condition, controlling for variables that significantly differed between clusters at a $p<.05$ level. All analyses were carried out using the SPSS Version 25, SAS Version 9.4, and GraphPad Prism Version 7.03.

\section{Results}

\section{Preliminary Analysis: Test of the Latent Structure of CPT}

Summary statistics and factor loadings for the PCA analysis are presented in Table 2. Sample adequacy for PCA analysis was evinced by a .74 Kaiser-Meyer-Olkin index and the significance AQ: 5 of the Bartlett's sphericity test, $\chi^{2}=(866.22,10), p<.001$. The PCA solution replicated the data matrices previously reported in the literature, which indicated the existence of a bifactorial latent structure of the CPT. The two factors obtained were used in subsequent analyses and interpreted as in a prior validation study (for further details, see González-Roz et al., 2018): Factor 1 "Persistence" and Factor 2 "Psychological inertia."

\section{Clusters of Smokers Based on Reinforcer Pathology Indicators}

A two-cluster solution was identified as the best fit by the aligned box criterion. Cluster 1 (C1) comprised $42 \%$ of the sample (128/305) and Cluster 2 (C2) included 58\% (177/305). In compar-

Table 2

Summary Statistics for the Cigarette Purchase Task Indices and Their Associated Latent Factor Loadings

\begin{tabular}{lrcc}
\hline & & \multicolumn{2}{c}{ Principal components } \\
\cline { 3 - 4 } \multicolumn{1}{c}{ Index $^{\mathrm{c}}$} & $M(S D)$ & $\begin{array}{c}\text { Factor } 1^{\mathrm{a}} \\
(\text { Persistence) }\end{array}$ & $\begin{array}{c}\text { Factor } 2^{\mathrm{b}} \\
\text { (Psychological Inertia) }\end{array}$ \\
\hline 1. Breakpoint & $.84(.58)$ & $\mathbf{. 9 5}$ & -.06 \\
2. $\mathrm{O}_{\max }$ & $1.01(.45)$ & $\mathbf{. 8 5}$ & .18 \\
3. P $_{\max }$ & $.36(.61)$ & $\mathbf{. 9 7}$ & -.19 \\
4. Elasticity & $-2.75(.62)$ & -.49 & -.37 \\
5. Intensity & $1.31(.18)$ & -.04 & $\mathbf{. 9 5}$ \\
\hline
\end{tabular}

Note. Factor loadings (i.e., $\geq .32$ ) are highlighted in bold.

${ }^{\mathrm{a}}$ Variance explained $=59.48 \% . \quad{ }^{\mathrm{b}}$ Variance explained $=19.61 \% . \quad{ }^{\mathrm{c}}$ Back transformed to $\log 10$. ison with smokers in $\mathrm{C} 1$, those grouped in $\mathrm{C} 2$ showed significantly higher DD rates $\left(M_{\mathrm{AUClogd}}=.32, S D=.25\right.$, vs. $M_{\mathrm{AUClogd}}=.45$, $S D=.27)$, but lower psychological inertia $(M=-.46, S D=.87$, vs. $M=.64, S D=.79)$, and persistence scores $(M=-.53, S D=$ .67 , vs. $M=.74, S D=.90)$.

Differences in sociodemographic, depression, and smokingrelated variables emerged across groups. Relative to individuals in $\mathrm{C} 1$, those in $\mathrm{C} 2$ showed higher depression severity $(p=.01)$, but a lower number of cigarettes smoked per day $(p<.001)$, nicotine dependence severity $(p<.001)$, and cotinine levels $(p=.001$; see Table 3).

\section{Relationship Between Cluster Membership and Abstinence Status by Treatment Condition}

Abstinence rates by cluster membership, treatment condition and follow-up assessment are displayed in Figure 1. At the end- F1 of-treatment, smokers falling into $\mathrm{C} 2$ showed significantly higher cessation rates $\left(76.3 \%\right.$ vs. $\left.61 \% ; \chi^{2}=8.291, p=.004, \phi=.16\right)$ and higher continuous abstinence $(M=15.66, S D=11.28 ; M=$ $10.68, S D=9.50), t(290)=-4.113, p=<.001$, Cohen's $d=$ 0.48 , compared to those in C1. At 6-month follow-up, differences dissipated and equal cessation rates were found across clusters in terms of either point prevalence abstinence $(\mathrm{C} 1=31.3 \%$ vs. $\mathrm{C} 2=$ $39.5 \% ; \chi^{2}=2.218, p=.14, \phi=.08$ ) or days of continuous abstinence $\left(M_{\mathrm{C} 1}=53.41, S D=86.05\right.$ vs. $M_{\mathrm{C} 2}=69.86, S D=$ 92.71), $t(282)=-1.58, p=.12$, Cohen's $d=-0.18$.

Table 4 shows results of the regression analyses examining the T4 association between treatment condition and abstinence status for each of the identified clusters. For those in $\mathrm{C} 1$, nicotine dependence severity significantly predicted posttreatment abstinence, $\chi^{2}(5)=13.18, p=.02, R^{2}=.14$, whereas cotinine and nicotine dependence severity were related to 6-month abstinence, $\chi^{2}(5)=$ $13.72, p=.02, R^{2}=.16$. For $\mathrm{C} 2$, neither the treatment condition nor the remaining variables tested predicted posttreatment abstinence status. At 6 months, nicotine dependence severity was the sole significant variable predicting abstinence, $\chi^{2}(5)=17.26, p=$ $.004, R^{2}=.13$.

\section{Discussion}

The main purposes of the present study were to identify clusters of treatment-seeking smokers based on the RP framework and to determine whether these patients responded differently to CBT and CBT + CM treatment. Two results are highlighted: (a) two clusters were identified based on cigarette demand and DD, C1 (characterized by excessive tobacco valuation) and $\mathrm{C} 2$ (characterized by steep discounting), and (b) CBT and CBT + CM promoted similar short- and long-term cessation rates regardless of cluster membership.

Cluster comparisons of RP indicators revealed that participants in $\mathrm{C} 1$ showed higher levels of demand as measured by the latent components of the CPT (i.e., psychological inertia and persistence), whereas those in $\mathrm{C} 2$ were mainly characterized by higher DD rates. Based on the overall patterns of the assessed RP facets, C1 was interpreted as "individuals with excessive tobacco valuation" and C2 as "steep discounters."

The fact that higher smoking-related variables were found in the cluster with higher persistence and psychological inertia (i.e., C1) 
Table 3

Cluster Differences in Sociodemographic and Smoking-Related Variables

\begin{tabular}{|c|c|c|c|c|c|c|}
\hline \multirow[b]{2}{*}{ Characteristic } & \multicolumn{2}{|c|}{ Cluster $1(n=128)$} & \multicolumn{2}{|c|}{ Cluster $2(n=177)$} & \multirow[b]{2}{*}{$p$} & \multirow[b]{2}{*}{ Effect size } \\
\hline & $M(S D)$ & $\%$ & $M(S D)$ & $\%$ & & \\
\hline Sex $(\%$ female $)$ & & 65.6 & & 68.9 & .54 & -.035 \\
\hline Age, years & $48.06(11.25)$ & & $49.15(12.21)$ & & .43 & -.26 \\
\hline Employment status (\% employed) & & 62.5 & & 59.9 & .64 & -.03 \\
\hline Monthly income (\%) & & & & & .21 & .12 \\
\hline$\leq \$ 692$ & & 23.4 & & 29.8 & & \\
\hline$\$ 693-\$ 1,383$ & & 29.8 & & 32.2 & & \\
\hline$\$ 1,384-\$ 2,305$ & & 32.3 & & 30.4 & & \\
\hline$\geq \$ 2,306$ & & 14.5 & & 7.6 & & \\
\hline Cigarettes per day & $24.69(9.35)$ & & $19.02(6.79)$ & & $<.001$ & .69 \\
\hline Years of regular smoking & $29.30(11.82)$ & & $29.41(11.64)$ & & .934 & -.01 \\
\hline Previous 24-hr quit attempts & $1.83(2.05)$ & & $2.40(3.14)$ & & .08 & -.22 \\
\hline BDI-II & $17.92(12.25)$ & & $22.08(13.02)$ & & .01 & -.33 \\
\hline FTND & $6.60(1.68)$ & & $5.56(1.85)$ & & $<.001$ & .58 \\
\hline $\mathrm{CO}(\mathrm{ppm})$ & $20.63(11.64)$ & & $20.85(14.48)$ & & .88 & -.01 \\
\hline Cotinine (ng/mL) & $2,742(1,921)$ & & $1,983(1,935)$ & 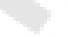 & .001 & .39 \\
\hline
\end{tabular}

Note. $\quad$ BDI-II $=$ second version of the Beck Depression Inventory; FTND $=$ Fagerström Test for Nicotine Dependence; CO $(\mathrm{ppm})=$ carbon monoxide in parts per million.

might suggest the greater relevance of demand over discounting when accounting for levels of consumption. This hypothesis has been recently tested by Acuff, Soltis, Dennhardt, Berlin, and Murphy (2018) in an empirical examination of the RP model in heavy drinkers. Greater levels of alcohol demand were directly related to higher alcohol consumption and related problems, whereas DD was uncorrelated with alcohol consumption.

Of note is that those with greater DD rates presented higher Beck Depression Inventory scores, which is consistent with evidence showing that negative mood relates to reduced salience of valued future goals in favor of immediate and less valued ones (Bickel et al., 2019; Szuhany, MacKenzie, \& Otto, 2018). Individuals with depression typically engage in low activity levels and perceive low reinforcement levels from their natural environment (Audrain-McGovern, Rodríguez, Rodgers, \& Cuevas, 2011), which gives them a propensity to prefer smaller, immediate reinforcers (i.e., staying in bed, using cigarettes) over larger delayed ones (i.e., engaging in substance-free alternative behaviors).

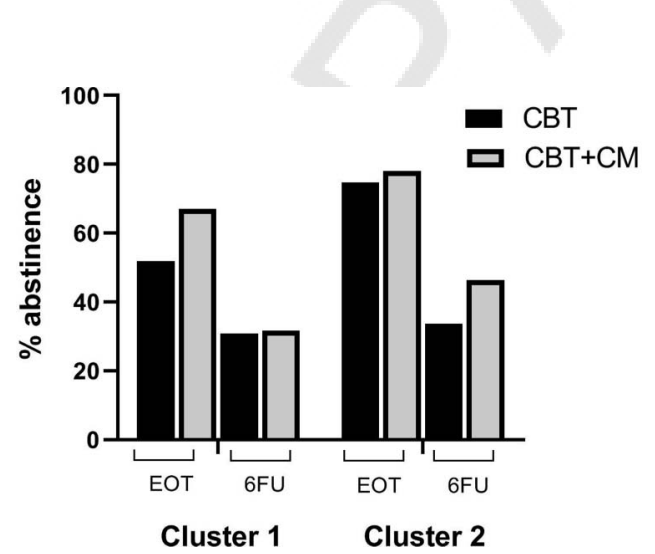

Figure 1. Point-prevalence abstinence rates at the end-of-treatment (EOT) and 6-month follow-up (6FU) by cluster membership and treatment condition. $\mathrm{CBT}=$ cognitive- behavioral treatment; $\mathrm{CBT}+\mathrm{CM}=$ cognitive-behavioral treatment plus contingency management.
$\mathrm{CBT}$ and $\mathrm{CBT}+\mathrm{CM}$ promoted similar cessation rates both at short-term and at long-term follow-up, regardless of cluster membership. These rates fall around the upper limit recorded in previous studies (Dallery, Raiff, \& Grabinski, 2013; Krishnan-Sarin et al., 2007). The remarkably high cessation rates might have occurred as a result of delivering treatment in a more intensive fashion than preceding studies (i.e., a higher number of sessions, and twice-weekly biochemical measures of smoking, with stronger monitoring effects) and the inclusion of an impulsivity-targeted component in the CBT protocol, such as problem solving. The lack of statistically significant differences between CBT and CBT + $\mathrm{CM}$ may be surprising given the strong evidence in support of their efficacy for the treatment of smoking (Cahill et al., 2015; Sigmon

Table 4

Treatment Condition as a Predictor of Smoking Status at Each Timeframe Assessment by Cluster Membership

\begin{tabular}{lcc}
\hline \multicolumn{1}{c}{ Cluster } & $\begin{array}{c}\text { Posttreatment } \\
\text { (8-week treatment), } \\
\text { OR }[95 \% \mathrm{CI}]\end{array}$ & $\begin{array}{c}\text { 6-Month follow-up, } \\
\text { OR }[95 \% \mathrm{CI}]\end{array}$ \\
\hline Cluster 1 & & \\
$\quad$ Cigarettes per day & $1.02[.98,1.08]$ & $1.01[.96,1.07]$ \\
Cotinine $(\mathrm{ng} / \mathrm{mL})$ & $1.00[1.00,1.00]$ & $1.00[.99,1.00]^{*}$ \\
BDI-II & $.99[.96,1.03]$ & $1.00[.97,1.04]$ \\
FTND & $.64[.47, .88]^{*}$ & $.71[.51, .97]^{*}$ \\
Treatment condition ${ }^{\mathrm{a}}$ & $1.19[.51,2.78]$ & $.52[.20,1.30]$ \\
Cluster 2 & & \\
Cigarettes per day & $1.02[.96,1.08]$ & $.96[.90,1.02]$ \\
Cotinine $(\mathrm{ng} / \mathrm{ml})$ & $1.00[1.00,1.00]$ & $1.00[1.00,1.00]$ \\
BDI-II & $.99[.97,1.03]$ & $1.01[.98,1.04]$ \\
FTND & $.85[.67,1.07]$ & $.78[.63, .95]^{*}$ \\
Treatment condition ${ }^{\mathrm{a}}$ & $1.20[.57,2.54]$ & $1.65[.84,3.24]$ \\
\hline
\end{tabular}

Note. $\quad$ OR $=$ odd ratio; $\mathrm{CI}=$ confidence interval; $\mathrm{BDI}-\mathrm{II}=$ second version of the Beck Depression Inventory; FTND = Fagerström Test for Nicotine Dependence.

${ }^{\text {a }}$ Cognitive-behavioral treatment was entered as the reference category. ${ }^{*} p<.05$. 
\& Patrick, 2012). A few factors may explain this result. First, treatment effects for $\mathrm{CM}$ tend to be less or null when compared to other active treatments, such as standard care (Cooney et al., 2017; Kirby, Marlowe, Festinger, Lamb, \& Platt, 1998). In our study, we added a CBT condition, which has proven to be an effective treatment for smoking cessation for individuals with high impulsivity (Morean et al., 2015). Second, the reinforcer magnitude used in this study (up to US\$342) may have been too low to produce a rewarding effect in the participants. There exist several studies showing that low-magnitude CM (US\$207.50 to US\$362.50) is effective in enhancing cessation rates (Dunn et al., 2010; Packer, Howell, McPherson, \& Roll, 2012). However, not all evidence supports it to facilitate substance use in difficult-to-treat populations (Dallery, Silverman, Chutuape, Bigelow, \& Stitzer, 2001; Romanowich \& Lamb, 2010; Silverman, Chutuape, Bigelow, \& Stitzer, 1999). Sound evidence of the necessity to increase the value of incentives has recently been shown by Harvanko et al. (2019). In this study, impulsive smokers in a high-magnitude CM condition (US\$773) showed enhanced CO reductions relative to those in a noncontingent control arm. Given that smokers with high DD struggle to initiate smoking abstinence (Krishnan-Sarin et al., 2007; Worley et al., 2018) and adhere to CM schedules (Harvanko et al., 2019), increasing the magnitude of incentives would have arguably led to superior CM effects (Dallery \& Raiff, 2012).

Despite these promising results, it should be noted that less than $40 \%$ of the participants in each cluster remained abstinent at 6 months. Also, the fact that we found nicotine dependence as a significant predictor of cessation outcomes suggests the need to further investigate innovative procedures such as episodic thinking (Chiou \& Wu, 2017; Stein et al., 2016; Stein, Tegge, Turner, \& Bickel, 2018) or shaping cessation reinforcement (Lamb, Kirby, Morral, Galbicka, \& Iguchi, 2010; Secades-Villa et al., 2019) to engender continuous abstinence. Nonetheless, this is preliminary evidence and more research needs to be done to investigate whether these interventions do lead to enhanced cessation rates in patients with RP.

The study findings need to be appraised in the context of several limitations. First, given the secondary nature of the study, it is not possible to elucidate whether CBT or $\mathrm{CM}$ accounted for the reported effects, so further adequate designs are needed to clarify this issue. Second, despite the relatively high sample size used, it could be that increasing the number of participants and their heterogeneity in RP indicators (e.g., more participants with shallow DD and high demand) might have led to a different number of clusters. Finally, this study relied on a 6-month follow-up; using a longer timeframe assessment could yield more definite results.

Despite the above limitations, this is novel clinical evidence that supports the existence of different subtypes of treatment-seeking smokers based on the interrelationship between cigarette demand and DD. These findings add to the limited data on the effectiveness of $\mathrm{CM}$ for smoking cessation across individuals with different clinical characteristics and suggest effects may persist beyond the period in which reinforcement is applied. Results also support the generalizability of CBT and CM strategies irrespective of patients' $\mathrm{RP}$ subtype. In the interest of allocating $\mathrm{CM}$ resources in a more efficient manner, offering CBT as a first-line treatment followed by $\mathrm{CM}$ for nontreatment responders would be expected to improve treatment targeting and customization, a pressing need in clinical contexts (Forster et al., 2019). Alternatively, novel treatment procedures tailored to cigarette demand and their combination with $\mathrm{CM}$ could be provided to enhance and extend the effects of CM.

\section{References}

Acuff, S. F., Soltis, K. E., Dennhardt, A. A., Berlin, K. S., \& Murphy, J. G. (2018). Evaluating behavioral economic models of heavy drinking among college students. Alcoholism, Clinical and Experimental Research, 42, 1304-1314. http://dx.doi.org/10.1111/acer.13774

Alessi, S. M., \& Petry, N. M. (2014). Smoking reductions and increased self-efficacy in a randomized controlled trial of smoking abstinencecontingent incentives in residential substance abuse treatment patients. Nicotine \& Tobacco Research, 16, 1436-1445. http://dx.doi.org/10 $.1093 / \mathrm{ntr} / \mathrm{ntu} 095$

American Psychiatric Association. (2000). Diagnostic and statistical manual of mental disorders (4th ed., text rev.). Washington, DC: Author.

Amlung, M., \& MacKillop, J. (2014). Clarifying the relationship between impulsive delay discounting and nicotine dependence. Psychology of Addictive Behaviors, 28, 761-768. http://dx.doi.org/10.1037/a0036726

Amlung, M., Yurasek, A., McCarty, K. N., MacKillop, J., \& Murphy, J. G. (2015). Area under the curve as a novel metric of behavioral economic demand for alcohol. Experimental and Clinical Psychopharmacology, 23, 168-175. http://dx.doi.org/10.1037/pha0000014

Audrain-McGovern, J., Rodríguez, D., Rodgers, K., \& Cuevas, J. (2011). Declining alternative reinforcers link depression to young adult smoking. Addiction, 106, 178-187. http://dx.doi.org/10.1111/j.1360-0443 .2010.03113.x

Barlow, P., McKee, M., Reeves, A., Galea, G., \& Stuckler, D. (2017). Time-discounting and tobacco smoking: A systematic review and network analysis. International Journal of Epidemiology, 46, 860-869. http://dx.doi.org/10.1093/ije/dyx060

Bickel, W. K., Athamneh, L. N., Basso, J. C., Mellis, A. M., DeHart, W. B., Craft, W. H., \& Pope, D. (2019). Excessive discounting of delayed reinforcers as a trans-disease process: Update on the state of the science. Current Opinion in Psychology, 30, 59-64. http://dx.doi.org/ 10.1016/j.copsyc.2019.01.005

Bickel, W. K., Jarmolowicz, D. P., Mueller, E. T., \& Gatchalian, K. M. (2011). The behavioral economics and neuroeconomics of reinforcer pathologies: Implications for etiology and treatment of addiction. Current Psychiatry Reports, 13, 406-415. http://dx.doi.org/10.1007/ s11920-011-0215-1

Bickel, W. K., Johnson, M. W., Koffarnus, M. N., MacKillop, J., \& Murphy, J. G. (2014). The behavioral economics of substance use disorders: Reinforcement pathologies and their repair. Annual Review of Clinical Psychology, 10, 641-677. http://dx.doi.org/10.1146/annurevclinpsy-032813-153724

Bickel, W. K., Marsch, L. A., \& Carroll, M. E. (2000). Deconstructing relative reinforcing efficacy and situating the measures of pharmacological reinforcement with behavioral economics: A theoretical proposal. Psychopharmacology, 153, 44-56. http://dx.doi.org/10.1007/ s002130000589

Bidwell, L. C., MacKillop, J., Murphy, J. G., Tidey, J. W., \& Colby, S. M. (2012). Latent factor structure of a behavioral economic cigarette demand curve in adolescent smokers. Addictive Behaviors, 37, 1257-1263. http://dx.doi.org/10.1016/j.addbeh.2012.06.009

Borges, A. M., Kuang, J., Milhorn, H., \& Yi, R. (2016). An alternative approach to calculating area-under-the-curve (AUC) in delay discounting research. Journal of the Experimental Analysis of Behavior, 106, 145-155. http://dx.doi.org/10.1002/jeab.219

Cahill, K., Hartmann-Boyce, J., \& Perera, R. (2015). Incentives for smoking cessation. Cochrane Database of Systematic Reviews, 5, CD004307. Chiou, W. B., \& Wu, W. H. (2017). Episodic future thinking involving the nonsmoking self can induce lower discounting and cigarette consump- 
tion. Journal of Studies on Alcohol and Drugs, 78, 106-112. http://dx .doi.org/10.15288/jsad.2017.78.106

Cooney, J. L., Cooper, S., Grant, C., Sevarino, K., Krishnan-Sarin, S., Gutierrez, I. A., \& Cooney, N. L. (2017). A randomized trial of contingency management for smoking cessation during intensive outpatient alcohol treatment. Journal of Substance Abuse Treatment, 72, 89-96. http://dx.doi.org/10.1016/j.jsat.2016.07.002

Dallery, J., \& Raiff, B. (2012). Monetary-based consequences for drug abstinence: Methods of implementation and some considerations about the allocation of finances in substance abusers. The American Journal of Drug and Alcohol Abuse, 38, 20-29. http://dx.doi.org/10.3109/ 00952990.2011.598592

Dallery, J., Raiff, B. R., \& Grabinski, M. J. (2013). Internet-based contingency management to promote smoking cessation: A randomized controlled study. Journal of Applied Behavior Analysis, 46, 750-764. http:// dx.doi.org/10.1002/jaba.89

Dallery, J., Silverman, K., Chutuape, M. A., Bigelow, G. E., \& Stitzer, M. L. (2001). Voucher-based reinforcement of opiate plus cocaine abstinence in treatment-resistant methadone patients: Effects of reinforcer magnitude. Experimental and Clinical Psychopharmacology, 9, 317-325. http://dx.doi.org/10.1037/1064-1297.9.3.317

Dunn, K. E., Sigmon, S. C., Reimann, E. F., Badger, G. J., Heil, S. H., \& Higgins, S. T. (2010). A contingency-management intervention to promote initial smoking cessation among opioid-maintained patients. Experimental and Clinical Psychopharmacology, 18, 37-50. http://dx.doi .org/10.1037/a0018649

Forster, S. E., DePhilippis, D., \& Forman, S. D. (2019). "I's" on the prize: A systematic review of individual differences in contingency management treatment response. Journal of Substance Abuse Treatment, 100, 64-83. http://dx.doi.org/10.1016/j.jsat.2019.03.001

AQ: 6 González-Roz, A., Secades-Villa, R., \& Alonso-Pérez, F. (2019). Effects of combining contingency management with behavioral activation for smokers with depression. Addiction Research and Theory, 27, 1-8. http://dx.doi.org/10.1080/16066359.2018.1463371

González-Roz, A., Secades-Villa, R., Weidberg, S., García-Pérez, Á., \& Reed, D. D. (2018). Latent structure of the CPT among treatmentseeking smokers with depression and its predictive validity on smoking abstinence. Nicotine \& Tobacco Research. Advance online publication. http://dx.doi.org/10.1093/ntr/nty236

Harvanko, A. M., Strickland, J. C., Slone, S. A., Shelton, B. J., \& Reynolds, B. A. (2019). Dimensions of impulsive behavior: Predicting contingency management treatment outcomes for adolescent smokers. Addictive Behaviors, 90, 334-340. http://dx.doi.org/10.1016/j.addbeh.2018 .11 .031

Heatherton, T. F., Kozlowski, L. T., Frecker, R. C., \& Fagerström, K. O. (1991). The Fagerström Test for Nicotine Dependence: A revision of the Fagerström Tolerance Questionnaire. British Journal of Addiction, 86, 1119-1127. http://dx.doi.org/10.1111/j.1360-0443.1991.tb01879.x

Holt, D. D., Green, L., \& Myerson, J. (2012). Estimating the subjective value of future rewards: Comparison of adjusting-amount and adjustingdelay procedures. Behavioural Processes, 90, 302-310. http://dx.doi .org/10.1016/j.beproc.2012.03.003

Japuntich, S. J., Lee, L. O., Pineles, S. L., Gregor, K., Joos, C. M., Patton, S. C., . . . Rasmusson, A. M. (2019). Contingency management and cognitive behavioral therapy for trauma-exposed smokers with and without posttraumatic stress disorder. Addictive Behaviors, 90, 136-142. http://dx.doi.org/10.1016/j.addbeh.2018.10.042

Johnson, M. W., \& Bickel, W. K. (2008). An algorithm for identifying nonsystematic delay-discounting data. Experimental and Clinical Psychopharmacology, 16, 264-274. http://dx.doi.org/10.1037/1064-1297 .16.3.264

Kirby, K. C., Marlowe, D. B., Festinger, D. S., Lamb, R. J., \& Platt, J. J. (1998). Schedule of voucher delivery influences initiation of cocaine abstinence. Journal of Consulting and Clinical Psychology, 66, 761767. http://dx.doi.org/10.1037/0022-006X.66.5.761

Koffarnus, M. N., Franck, C. T., Stein, J. S., \& Bickel, W. K. (2015). A modified exponential behavioral economic demand model to better describe consumption data. Experimental and Clinical Psychopharmacology, 23, 504-512. http://dx.doi.org/10.1037/pha0000045

Koffarnus, M. N., \& Kaplan, B. A. (2018). Clinical models of decision making in addiction. Pharmacology, Biochemistry, and Behavior, 164, 71-83. http://dx.doi.org/10.1016/j.pbb.2017.08.010

Krishnan-Sarin, S., Reynolds, B., Duhig, A. M., Smith, A., Liss, T., McFetridge, A., . . . Potenza, M. N. (2007). Behavioral impulsivity predicts treatment outcome in a smoking cessation program for adolescent smokers. Drug and Alcohol Dependence, 88, 79-82. http://dx.doi .org/10.1016/j.drugalcdep.2006.09.006

Lamb, R. J., Kirby, K. C., Morral, A. R., Galbicka, G., \& Iguchi, M. Y. (2010). Shaping smoking cessation in hard-to-treat smokers. Journal of Consulting and Clinical Psychology, 78, 62-71. http://dx.doi.org/10 $.1037 / \mathrm{a} 0018323$

López-Núñez, C., Secades-Villa, R., Peña-Suárez, E., FernándezArtamendi, S., \& Weidberg, S. (2017). Income levels and response to contingency management for smoking cessation. Substance Use \& Misuse, 52, 875-883. http://dx.doi.org/10.1080/10826084.2016.1264973

Mackillop, J., Murphy, C. M., Martin, R. A., Stojek, M., Tidey, J. W., Colby, S. M., \& Rohsenow, D. J. (2016). Predictive validity of a cigarette purchase task in a randomized controlled trial of contingent vouchers for smoking in individuals with substance use disorders. Nicotine \& Tobacco Research, 18, 531-537. http://dx.doi.org/10.1093/ntr/ ntv233

MacKillop, J., Murphy, J. G., Ray, L. A., Eisenberg, D. T., Lisman, S. A., Lum, J. K., \& Wilson, D. S. (2008). Further validation of a cigarette purchase task for assessing the relative reinforcing efficacy of nicotine in college smokers. Experimental and Clinical Psychopharmacology, 16, 57-65. http://dx.doi.org/10.1037/1064-1297.16.1.57

McPherson, S. M., Burduli, E., Smith, C. L., Herron, J., Oluwoye, O., Hirchak, K., . . Roll, J. M. (2018). A review of contingency management for the treatment of substance-use disorders: Adaptation for underserved populations, use of experimental technologies, and personalized optimization strategies. Substance Abuse and Rehabilitation, 9, 43-57. http://dx.doi.org/10.2147/SAR.S138439

Morean, M. E., Kong, G., Camenga, D. R., Cavallo, D. A., Carroll, K. M., Pittman, B., \& Krishnan-Sarin, S. (2015). Contingency management improves smoking cessation treatment outcomes among highly impulsive adolescent smokers relative to cognitive behavioral therapy. Addictive Behaviors, 42, 86-90. http://dx.doi.org/10.1016/j.addbeh.2014.11 .009

Murphy, C. M., MacKillop, J., Martin, R. A., Tidey, J. W., Colby, S. M., \& Rohsenow, D. J. (2017). Effects of varenicline versus transdermal nicotine replacement therapy on cigarette demand on quit day in individuals with substance use disorders. Psychopharmacology, 234, $2443-$ 2452. http://dx.doi.org/10.1007/s00213-017-4635-4

Myerson, J., Green, L., \& Warusawitharana, M. (2001). Area under the curve as a measure of discounting. Journal of the Experimental Analysis of Behavior, 76, 235-243. http://dx.doi.org/10.1901/jeab.2001.76-235

Nighbor, T. D., Zvorsky, I., Kurti, A. N., Skelly, J. M., Bickel, W. K., Reed, D. D., . . Higgins, S. T. (2019). Examining interrelationships between the Cigarette Purchase Task and delay discounting among pregnant women. Journal of the Experimental Analysis of Behavior, 111, 405-415. http://dx.doi.org/10.1002/jeab.499

O'Connor, R. J., Heckman, B. W., Adkison, S. E., Rees, V. W., Hatsukami, D. K., Bickel, W. K., \& Cummings, K. M. (2016). Persistence and amplitude of cigarette demand in relation to quit intentions and attempts. Psychopharmacology, 233, 2365-2371. http://dx.doi.org/10.1007/ s00213-016-4286-x 
Packer, R. R., Howell, D. N., McPherson, S., \& Roll, J. M. (2012). Investigating reinforcer magnitude and reinforcer delay: A contingency management analog study. Experimental and Clinical Psychopharmacology, 20, 287-292. http://dx.doi.org/10.1037/a0027802

Petry, N. M., Alessi, S. M., Olmstead, T. A., Rash, C. J., \& Zajac, K. (2017). Contingency management treatment for substance use disorders: How far has it come, and where does it need to go? Psychology of Addictive Behaviors, 31, 897-906. http://dx.doi.org/10.1037/ adb0000287

Petry, N. M., Alessi, S. M., \& Rash, C. J. (2013). Contingency management treatments decrease psychiatric symptoms. Journal of Consulting and Clinical Psychology, 81, 926-931. http://dx.doi.org/10.1037/ a0032499

Rash, C. J., Petry, N. M., \& Alessi, S. M. (2018). A randomized trial of contingency management for smoking cessation in the homeless. Psychology of Addictive Behaviors, 32, 141-148. http://dx.doi.org/10.1037/ adb0000350

Renaud, J. M., \& Halpern, M. T. (2010). Clinical management of smoking cessation: Patient factors affecting a reward-based approach. Patient Preference and Adherence, 4, 441-450.

Rohsenow, D. J., Martin, R. A., Tidey, J. W., Colby, S. M., \& Monti, P. M. (2017). Treating smokers in substance treatment with contingent vouchers, nicotine replacement and brief advice adapted for sobriety settings. Journal of Substance Abuse Treatment, 72, 72-79. http://dx.doi.org/10 $.1016 /$ j.jsat.2016.08.012

Romanowich, P., \& Lamb, R. J. (2010). Effects of escalating and descending schedules of incentives on cigarette smoking in smokers without plans to quit. Journal of Applied Behavior Analysis, 43, 357-367. http://dx.doi.org/10.1901/jaba.2010.43-357

SAS Institute Inc. (2016). SAS Enterprise Miner 14.2: High-Performance Procedures. Cary, NC: Author.

Sayegh, C. S., Huey, S. J., Zara, E. J., \& Jhaveri, K. (2017). Follow-up treatment effects of contingency management and motivational interviewing on substance use: A meta-analysis. Psychology of Addictive Behaviors, 31, 403-414. http://dx.doi.org/10.1037/adb0000277

Secades-Villa, R., García-Rodríguez, O., López-Núñez, C., Alonso-Pérez, F., \& Fernández-Hermida, J. R. (2014). Contingency management for smoking cessation among treatment-seeking patients in a community setting. Drug and Alcohol Dependence, 140, 63-68. http://dx.doi.org/ 10.1016/j.drugalcdep.2014.03.030

Secades-Villa, R., López-Núñez, C., Weidberg, S., González-Roz, A., \& Alonso-Pérez, F. (2019). A randomized controlled trial of contingency management for smoking abstinence versus contingency management for shaping cessation: One-year outcome. Experimental and Clinical Psychopharmacology. Advance online publication. http://dx.doi.org/10 $.1037 /$ pha0000269

Secades-Villa, R., Pericot-Valverde, I., \& Weidberg, S. (2016). Relative reinforcing efficacy of cigarettes as a predictor of smoking abstinence among treatment-seeking smokers. Psychopharmacology, 233, 31033112. http://dx.doi.org/10.1007/s00213-016-4350-6

Sigmon, S. C., \& Patrick, M. E. (2012). The use of financial incentives in promoting smoking cessation. Preventive Medicine, 55, S24-S32. http:// dx.doi.org/10.1016/j.ypmed.2012.04.007

Silverman, K., Chutuape, M. A., Bigelow, G. E., \& Stitzer, M. L. (1999). Voucher-based reinforcement of cocaine abstinence in treatment-resistant methadone patients: Effects of reinforcement magnitude. Psychopharmacology, 146, 128-138. http://dx.doi.org/10 $.1007 / \mathrm{s} 002130051098$

Stein, J. S., Koffarnus, M. N., Snider, S. E., Quisenberry, A. J., \& Bickel, W. K. (2015). Identification and management of nonsystematic purchase task data: Toward best practice. Experimental and Clinical Psychopharmacology, 23, 377-386. http://dx.doi.org/10.1037/pha0000020

Stein, J. S., Tegge, A. N., Turner, J. K., \& Bickel, W. K. (2018). Episodic future thinking reduces delay discounting and cigarette demand: An investigation of the good-subject effect. Journal of Behavioral Medicine, 41, 269-276. http://dx.doi.org/10.1007/s10865-017-9908-1

Stein, J. S., Wilson, A. G., Koffarnus, M. N., Daniel, T. O., Epstein, L. H., \& Bickel, W. K. (2016). Unstuck in time: Episodic future thinking reduces delay discounting and cigarette smoking. Psychopharmacology, 233, 3771-3778. http://dx.doi.org/10.1007/s00213-016-4410-y

Szuhany, K. L., MacKenzie, D., Jr., \& Otto, M. W. (2018). The impact of depressed mood, working memory capacity, and priming on delay discounting. Journal of Behavior Therapy and Experimental Psychiatry, 60, 37-41. http://dx.doi.org/10.1016/j.jbtep.2018.03.001

Tabachnick, B. G., \& Fidell, L. S. (2000). Using multivariate statistics. Boston, MA: Allyn \& Bacon.

Tidey, J. W., Rohsenow, D. J., Kaplan, G. B., Swift, R. M., \& Reid, N. (2011). Effects of contingency management and bupropion on cigarette smoking in smokers with schizophrenia. Psychopharmacology, 217, 279-287. http://dx.doi.org/10.1007/s00213-011-2282-8

Tomko, R. L., Bountress, K. E., \& Gray, K. M. (2016). Personalizing substance use treatment based on pre-treatment impulsivity and sensation seeking: A review. Drug and Alcohol Dependence, 167, 1-7. http://dx.doi.org/10.1016/j.drugalcdep.2016.07.022

Weidberg, S., Secades-Villa, R., García-Pérez, Á., González-Roz, A., \& Fernández-Hermida, J. R. (2019). The synergistic effect of cigarette demand and delay discounting on nicotine dependence among treatmentseeking smokers. Experimental and Clinical Psychopharmacology, 27, 146-152. http://dx.doi.org/10.1037/pha0000248

Worley, M. J., Isgro, M., Heffner, J. L., Lee, S. Y., Daniel, B. E., \& Anthenelli, R. M. (2018). Predictors of reduced smoking quantity among recovering alcohol dependent men in a smoking cessation trial. Addictive Behaviors, 84, 263-270. http://dx.doi.org/10.1016/j.addbeh.2018.05.004

Received February 22, 2019

Revision received July 10, 2019

Accepted July 10, 2019 